\title{
THE LEGAL FUNDAMENTALS FOR THE PREVENTION OF CAPITAL OUTFLOW FROM THE RUSSIAN FEDERATION
}

\author{
Elena V. Ryabova \\ International Law Institute's Volzhsky Branch, Volzhsky, Russian Federation
}

Alina A. Nikolaeva

Volgograd State University’s Volzhsky Branch, Volzhsky, Russian Federation

\begin{abstract}
Introduction: the identification and analysis of the causes and factors, including the gaps in the legislation, generating an increase in the capital outflow, as well as the improvement of the currency, investment and tax legislation are relevant and important issues. Purpose: to study the problems of the legal regulation to prevent the outflow of capital from the Russian Federation. Methods: the fundamental categories and principles of materialistic dialectics, the generally accepted methods of comparative law became the methodological framework for solving the tasks. As part of the study of the legal foundation to prevent the outflow of domestic capital abroad, the authors also used the methods of analysis and synthesis, functional and systematic approaches, and the formal legal and statistical methods. Results: grounded in the paper the author's point of view is based on the study of the international conventions, treaties and agreements to which Russia is a party, and the domestic legal acts regulating relations in the field of preventing the outflow of domestic capital abroad, as well as the opinion of the competent academic community. Conclusions: the study identified the characteristic features of the process of capital outflow from Russia and developed a list of recommendations aimed at improving the measures of the state legal regulation in the field of combating the outflow of capital abroad.
\end{abstract}

Key words: cross-border movement of capital, capital outflow, net capital outflow, legal regulation, offshore.

Citation. Ryabova E.V., Nikolaeva A.A. The Legal Fundamentals for the Prevention of Capital Outflow from the Russian Federation. Legal Concept, 2019, vol. 18, no. 3, pp. 84-89. (in Russian). DOI: https://doi.org/10.15688/ lc.jvolsu.2019.3.12

УДК 347.1(470.45)

Дата поступления статьи: 01.06.2019

ББК 67.404 .01 Дата принятия статьи: 20.06.2019

\section{ПРАВОВЫЕ ОСНОВЫ ПРЕДОТВРАЩЕНИЯ ОТТОКА КАПИТАЛА ИЗ РОССИЙСКОЙ ФЕДЕРАЦИИ}

Елена Владимировна Рябова

Международный юридический институт (Волжский филиал), г. Волжский, Российская Федерация

\section{Алина Альбертовна Николаева}

Волгоградский государственный университет (Волжский филиал), г. Волжский, Российская Федерация

Введение: выявление и анализ причин и факторов, в том числе пробелов в законодательстве, порождающих увеличение объемов оттока капитала, а также совершенствование валютного, инвестиционного и налогового законодательства - актуальные и значимые вопросы. Цель: исследование проблем нормативно-правового регулирования предотвращения оттока капитала из Российской Федерации. Методы: методологической базой для решения поставленных задач стали фундаментальные категории и принципы материалистической диалектики, общепринятые методы компаративного правоведения. В рамках исследова- 
ния правовых основ предотвращения оттока отечественного капитала за рубеж также применялись анализ и синтез, функциональный и системный подходы, формально-юридический и статистический методы. Результаты: обоснованная в работе авторская позиция опирается на исследование международных конвенций, договоров и соглашений, участницей которых является Россия, и отечественных нормативноправовых актов, регулирующих отношения в области предотвращения оттока отечественного капитала за рубеж, а также мнения компетентной научной среды. Выводы: в результате исследования выявлены характерные особенности процесса оттока капитала из России, разработан перечень рекомендаций, направленных на совершенствование мер государственно-правового регулирования в сфере противодействия выводу капитала за рубеж.

Ключевые слова: трансграничное движение капитала, отток капитала, чистый вывоз капитала, правовое регулирование, офшор.

Цитирование. Рябова Е. В., Николаева А. А. Правовые основы предотвращения оттока капитала из Российской Федерации // Legal Concept = Правовая парадигма. - 2019. - T. 18, № 3. - C. 84-89. - DOI: https:// doi.org/10.15688/lc.jvolsu.2019.3.12

\section{Введение}

В условиях финансовой нестабильности особую важность приобретают вопросы, связанные с оттоком капитала из страны. Масштабы вывоза капитала за рубеж с каждым годом принимают более неконтролируемые обороты, а действующая система валютного регулирования не в силах должным образом обеспечить баланс между притоком и оттоком капитала.

С начала 1994 г. в России наблюдался стабильный отток капитала за рубеж, усиливающийся во время финансовых кризисов. Исключением стал период с 2006 по 2007 г., когда сальдо движения капитала было положительным. Согласно данным Центробанка России отток капитала в 2017 г. ускорился почти в 2 раза, а в 2018 г. увеличился уже в 2,7 раза, до $\$ 67,5$ млрд, по сравнению с 2017 годом. При этом масштабы оттока капитала за рубеж с 1994 г. превысили совокупный объем притока прямых иностранных инвестиций, займы и кредиты международных финансовых организаций и оказание двусторонней финансовой помощи развитых стран [1, с. 102].

Несмотря на высокую степень изученности отечественными исследователями вопроса о регулировании трансграничного движения финансовых активов, до сих пор не разработана единая концепция, благодаря которой можно определить необходимость введения государственного контроля над оттоком капитала и пределы действия данных контрольных мер.

\section{Основы}

\section{нормативно-правового регулирования} отношений, связанных с оттоком капитала из Российской Федерации

Одним из наиболее актуальных и значимых вопросов в рамках данного исследования является совершенствование валютного, инвестиционного и налогового законодательства. РФ является участницей большого количества международных договоров, соглашений и конвенций, в особенности направленных на регулирование инвестиционных отношений.

В марте 1965 г. в Вашингтоне заключена Конвенция об урегулировании инвестиционных споров между государствами и физическими или юридическими лицами других государств, практическая цель которой заключается в создании специализированного международного учреждения - Центра по урегулированию инвестиционных споров (МЦУИС). К Конвенции присоединились порядка 150 стран, РФ подписала документ еще в 1992 г., однако до сих пор не ратифицировала его.

В 1985 г. в Сеуле заключена Конвенция об учреждении Многостороннего агентства по гарантиям инвестиций (МАГИ). Главная цель МАГИ - поддержка развития зарубежного инвестирования, содействие привлечению иностранных капиталовложений в развивающиеся страны с целью их социально-экономического развития. РФ подписала конвенцию в сентябре 1992 г., с декабря 1992 г. является ее участницей.

Основополагающие принципы порядка и условий иностранного инвестирования вклю- 
чают соглашения (ТРИМс, ГАТС, ТРИПС), которые действуют в рамках Всемирной торговой организации и были заключены в Марракеше в апреле 1994 года. Данные акты были ратифицированы Россией в августе 2012 года.

В 2014 г. Россия с определенными оговорками ратифицировала заключенную в Страсбурге в 1988 г. «Конвенцию о взаимной административной помощи по налоговым делам» [2]. Документ вступил в законную силу 1 июля 2015 г., однако его действие распространяется лишь на оказание административной помощи в отношении налоговых периодов или начислений, определенных в п. 6 ст. 28 Конвенции.

Широкую область применения получили двусторонние соглашения стран в сфере регулирования таких вопросов, как: поощрение и взаимная защита капиталовложений, избежание двойного налогообложения. Эффективность подобного рода соглашений подтверждает тот факт, что Россия заключила с иностранными государствами порядка 80 международных соглашений о поощрении и взаимной защите капитальных вложений и инвестиций и 85 конвенций и соглашений в области избежания двойного налогообложения.

Правовая основа обмена финансовой информацией между странами: Соглашение компетентных органов 27 января 2016 г. и Соглашение компетентных органов об автоматическом обмене финансовой информацией от 29 октября 2014 г., подписанные ФНС РФ в мае 2016 года. В 2018 г. Россия приступила к обмену информацией согласно Стандарту об автоматическом обмене информацией о финансовых счетах (Common Reporting Standard). Механизм информационного обмена должен способствовать снижению оттока капитала в офшоры и повышению уровня налоговой и финансовой прозрачности путем предоставления данных о счетах и финансовых операциях нерезидентов для налоговых органов стран - участниц Соглашения.

Формат автоматического обмена информацией и конкретный перечень государств и территорий, с которыми будет происходить данный обмен, опубликован на сайте ФНС РФ и определен Приказами ФНС России от 04.12.2018 № MMB-7-17/784@, № MMB-7-17/ 785@. Кроме того, Правительством РФ принято Постановление от 09.04.2018 № 428, в соответствии с которым утвержден порядок обмена финансовой информацией и страновых отчетов между ФНС России и компетентными органами иностранных государств, установлены необходимые требования защиты предоставляемых данных. В целях реализации механизма международного автоматического обмена информацией принят Федеральный закон от 27.11.2017 № 340-Ф3, согласно положениям которого установлена обязанность отечественных организаций предоставлять финансовую информацию о клиентах нерезидентах РФ и их счетах.

Ранее с 1 января 2015 г. в действие вступил так называемый первый антиофшорный Федеральный закон № 376-Ф3 (ред. от 12.11.2018), согласно которому отечественные налогоплательщики обязаны раскрывать информацию о прямом или же косвенном участии в деятельности зарубежных организаций. Представление подобной информации позволит составить более полное представление о применении представителями крупного бизнеса офшорных юрисдикций.

Основным актом, который регламентирует порядок валютного контроля в России, устанавливает основные принципы совершения валютных операций, является Федеральный закон от 10.12.2003 № 173-Ф3 «О валютном регулировании и валютном контроле» [8].

В августе 2017 г. была принята Инструкция Банка России № 181-И, которая регламентирует порядок представления информации при осуществлении валютных операций. Для оформления экспортной внешнеторговой сделки введен порядок постановки контрактов на учет в банковских учреждениях путем присвоения им уникальных номеров. В результате банк обязан осуществлять контроль не только над совершением валютной операции, но и над оформлением внешнеторговых операций [7]. Исключено основание отказа банка в постановке контракта на учет, более не действует справка о валютных операциях, необходимая ранее для отслеживания движения валютных средств по валютным счетам резидента. В итоге требования обновленного порядка совершения валютных операций приводят к большей либерализации валютного контроля.

Правительством было принято Распоряжение от 05.05.2017 № 870-р. Документ опре- 
деляет понятие «сомнительные финансовые операции», их характерные черты, порядок предупреждения и пресечения их совершения.

Стоит отметить, что в 2017-2018 гг. одной из наиболее актуальных тем стал вопрос о создании механизма правового регулирования криптовалюты в РФ. По мнению специалистов, криптовалюта может стать идеальным инструментом, который поспособствует несанкционированному вывозу капитала за рубеж. Так, в январе 2018 г. Министерством финансов РФ было предложено на законодательном уровне урегулировать вопрос о цифровых активах, подготовив Проект Федерального закона «О цифровых финансовых активах» [3]. Законопроект регламентирует особенности выпуска, обращения и обмена цифровых финансовых активов.

Кроме того, в целях стимулирования репатриации «сбежавших» капиталов применяется амнистия для капиталов, находящихся в офшорных территориях, но желающих вернуться обратно в РФ. В декабре 2014 г. в условиях нестабильной экономической обстановки Президент РФ в послании Федеральному собранию отметил необходимость проведения полной амнистии капиталов, желающих вернуться в РФ. Принятый Федеральный закон № 140-Ф3 [6] затронул вопросы освобождения от ответственности лиц, информация о которых содержится в декларации. Декларант освобождался: от уголовной ответственности; от административной ответственности; от ответственности за совершение налоговых правонарушений. Однако результаты амнистии могли быть в десятки раз больше в случае принятия законодателем более радикальных правил амнистии. В конце декабря 2017 г. Президент РФ предложил продлить срок амнистии капитала в связи с ужесточением условий зарубежных санкций.

Второй этап декларирования прошел с 1 марта 2018 по 28 февраля 2019 г. в целом на аналогичных условиях. При представлении декларации в ходе второго этапа предусмотренные гарантии предоставляются лишь в отношении тех деяний, которые были совершены до 1 января 2018 г., но в отличие от предыдущего этапа задекларировать можно не только действующие, но и закрытые до 1 января 2018 г. счета.

\section{Выводы}

Анализ данных о капитале, вывозимом из России за рубеж, отражает тенденции увеличения объема вывоза капитала из России на фоне сокращения объемов мирового рынка прямых иностранных инвестиций.

Важно отметить, что на современном этапе специфика развития экономических отношений заключается в изменении соотношения стоимостных и материально-вещественных форм вывозимого капитала в сторону роста нематериальных активов. В результате стоимостные, материальные и вещественные формы оттока капитала дополнены новыми формами: интеллектуальной, человеческой и социальной. Однако, несмотря на трансформацию форм и видов оттока капитала, сущность данного процесса остается неизменной, капитал по-прежнему вывозится с целью инвестирования и получения прибыли.

В итоге вывоз капитала за рубеж способен оказывать дуалистичное влияние на отечественную экономику [5, с. 14]: как отрицательное, так и положительное. Вывоз капитала за границу мог способствовать экономическому развитию РФ, если бы приобретенные за рубежом активы дополняли и развивали производственный процесс в России.

Однако на сегодняшний момент отток капитала (а его показатели достаточно высоки) за рубеж оказывает негативное влияние на процесс экономического развития страны, сокращает ее инвестиционный потенциал [4], дестабилизирует финансовую, денежно-кредитную и валютную системы, замедляет процесс обновления материально-технической базы производства во всех секторах экономики.

Стоит отметить, что отечественное законодательство, регулирующее отношения в области оттока капитала, в целом гармонизировано с международным правом. Вместе с тем вопросы национального регулирования отношений, связанных с оттоком капитала, отражены в рамках инвестиционного, валютного и налогового законодательства.

Нормативно-правовая база в области регулирования трансграничного движения капитала обладает дуалистичным характером. С одной стороны, Россия стремится к либерализации трансграничного движения капита- 


\section{ТЕОРИЯ И ПРАКТИКА ГОСУДАРСТВЕННО-ПРАВОВОГО РАЗВИТИЯ}

ла с целью привлечения зарубежных инвесторов. С другой стороны, анализ изменений отечественного законодательства отражает попытки законодателя в некоторой степени ограничить вывод капитала за рубеж.

Подход к решению проблемы оттока капитала должен быть комплексным и всесторонним. Преодолеть тенденцию вывоза капитала возможно путем разработки целенаправленной государственной стратегии, которая должна быть подкреплена соответствующей правовой базой и направлена на совершенствование мер регулирования движения капитала.

\section{Заключение}

Резюмируя вышеизложенное, можно заключить, что изменение динамики вывода капитала за рубеж зависит от совокупности взаимосвязанных факторов, направленных на устранение причин, стимулирующих перемещение российского капитала за границу: создание эффективной институциональной среды; «потепление» инвестиционного климата в стране; создание привлекательных и доступных инвестиционных проектов и наличие соответствующего перечня гарантий; установление как политической, так и экономической (финансовой) стабильности в России; плодотворная борьба с коррупцией и уменьшением оборота «теневого» капитала.

\section{СПИСОК ЛИТЕРАТУРЫ}

1. Андрианов, В. Д. Причины, масштабы и экономические последствия оттока капитала из России / В. Д. Андрианов // Россия: тенденции и перспективы развития. - 2016. - № 11 (ч. 1). C. $100-110$.

2. Конвенция о взаимной административной помощи по налоговым делам (Заключена в г. Страсбурге 25.01.1988). - Доступ из справ.-правовой системы «КонсльтантПлюс». - Режим доступа: http:// www.consultant.ru/document/cons_doc_LAW_186124/ (дата обращения: 11.06.2019).

3. Проект Федерального закона № 419059-7 «О цифровых финансовых активах» (ред., внесенная в ГД ФС РФ, текст по состоянию на 20.03.2018). Доступ из справ.-правовой системы «КонсультантПлюс». - Режим доступа: http://www.consultant.ru/ cons/cgi/online.cgi?req $=$ doc $\&$ base $=$ PRJ $\& n=170084$ $\& \mathrm{dst}=1000000001$ (дата обращения: 14.06.2019).
4. Симаева, Е. П. Проблемы правового обеспечения инвестиционной безопасности в условиях финансовой нестабильности / Е. П. Симаева // Вестник Волгоградского государственного университета. Серия 5, Юриспруденция. - 2012. - № 2 (17). C. 144-147.

5. Сулименко, О. В. Функционирование российского капитала за рубежом и его влияние на национальную экономику : дис. ... канд. экон. наук / Сулименко Олег Вячеславович. - Ростов н/Д, 2016. $-189 \mathrm{c}$.

6. Федеральный закон от 08.06.2015 № 140-Ф3 (ред. от 29.05.2019) «О добровольном декларировании физическими лицами активов и счетов (вкладов) в банках и о внесении изменений в отдельные законодательные акты РФ». - Доступ из справ.-правовой системы «КонсультантПлюс». - Режим доступа: http:// www.consultant.ru/document/cons_doc_LAW_180745/ (дата обращения: 14.06.2019).

7. Федеральный закон от 10.07.2002 № 86-Ф3 (ред. от 06.06.2019) «О Центральном банке РФ (Банке России)». - Доступ из справ.-правовой системы «КонсультантПлюс». - Режим доступа: http://www. consultant.ru/document/cons_doc_LAW_37570/ (дата обращения: 02.06.2019).

8. Федеральный закон от 10.12.2003 № 173-Ф3 (ред. от 25.12.2018) «О валютном регулировании и валютном контроле». - Доступ из справ.-правовой системы «КонсультантПлюс». - Режим доступа: http:// www.consultant.ru/document/cons_doc_LAW_45458/ (дата обращения: 12.06.2019).

\section{REFERENCES}

1. Andrianov V.D. Prichiny, masshtaby i ekonomicheskie posledstviya ottoka kapitala iz Rossii [The Reasons, Scopes and Economic Consequences of Capital Outflow from Russia]. Rossiya: tendentsii $i$ perspektivy razvitiya [Russia: Trends and Prospects of Development], 2016, no. 11 (part 1), pp. 100-110.

2. Konventsiya o vzaimnoy administrativnoy pomoshchi po nalogovym delam (Zaklyuchena $v$ g. Strasburge 25.01.1988) [The Convention on Mutual Administrative Assistance in Tax Matters (Concluded at Strasbourg 25.01.1988)]. URL: http://www. consultant.ru/document/cons_doc_LAW_186124/ (accessed 11 June 2019).

3. Proekt Federalnogo zakona № 419059-7 "O tsifrovykh finansovykh aktivakh» (red., vnesennaya $v$ GD FS RF, tekst po sostoyaniyu na 20.03.2018) [The Draft of Federal Law No. 419059-7 “'On Digital of Financial Assets" (ed., introduced in the State Duma of the Federal Assembly of the Russian Federation, the text on 20.03.2018)]. URL: http://www.consultant.ru/cons/cgi/ 
online.cgi?req $=$ doc\&base $=$ PRJ\&n $=170084 \& d s t=100000001$ (accessed 14 June 2019).

4. Simaeva E.P. Problemy pravovogo obespecheniya investitsionnoy bezopasnosti $\mathrm{v}$ usloviyakh finansovoy nestabilnosti [Problems of Legal Support of Investment Security in Conditions of Financial Instability]. Vestnik Volgogradskogo gosudarstvennogo universiteta. Seriya 5, Yurisprudentsiya [Science Journal of Volgograd State University. Jurisprudence], 2012, no. 2 (17), pp. 144-147.

5. Sulimenko O.V. Funktsionirovanie Rossiyskogo kapitala za rubezhom i ego vliyanie na natsionalnuyu ekonomiku: dis. ... kand. ekon. nauk [Functioning of Russian Capital Abroad and its Impact on the National Economy. Cand. econ. sci. diss.]. Rostov on Don, 2016. 189 p.

6. Federalnyy zakon ot 08.06.2015 № 140-FZ (red. ot 29.05.2019) «O dobrovolnom deklarirovanii fizicheskimi litsami aktivov i schetov (vkladov) $v$ bankakh $i$ o vnesenii izmeneniy $v$ otdelnye zakonodatelnye akty $R F$ » [The Federal Law on 08.06.2015 No. 140-FZ(ed. on 29.05.2019) “On Voluntary Declaration of Assets and Accounts (Deposits) by Individuals in Banks and on Amendments to Certain Legislative Acts of the Russian Federation"]. URL: http:// www.consultant.ru/document/cons_doc_LAW_ 180745/ (accessed 14 June 2019).

7. Federalnyy zakon ot 10.07.2002 № 86-FZ (red. ot 06.06.2019) «O Tsentralnom banke $R F$ (Banke Rossii)» [The Federal Law on 10.07.2002 No. 86-FZ (ed. on 06.06.2019) “On the Central Bank of the Russian Federation (Bank of Russia)"]. URL: http:// www.consultant.ru/document/cons_doc_LAW_ 37570/ (accessed 02 June 2019).

8. Federalnyy zakon ot 10.12.2003 № 173-FZ(red. ot 25.12.2018) «O valyutnom regulirovanii $i$ valyutnom kontrole» [The Federal Law on 10.12.2003 No. 173-FZ(ed. on 25.12.2018) "On currency regulation and currency control”]. URL: http://www.consultant.ru/document/ cons_doc_LAW_45458/(accessed 12 June 2019).

\section{Information about the Authors}

Elena V. Ryabova, Candidate of Sciences (Jurisprudence), Associate Professor, Department of Theory of Law and State Legal Disciplines, International Law Institute's Volzhsky Branch, Bolshevistskaya St., 7, 404106 Volzhsky, Russian Federation, ryabovaev@vgi.volsu.ru, https://orcid.org/0000-0003-4831-0270

Alina A. Nikolaeva, Master Student, Volgograd State University's Volzhsky Branch, 40 Let Pobedy St., 11, 404133 Volzhsky, Russian Federation, ob.otdel@vgi.volsu.ru, https://orcid.org/0000-0002$7702-6511$

\section{Информация об авторах}

Елена Владимировна Рябова, кандидат юридических наук, доцент кафедры теории права и государственно-правовых дисциплин, Международный юридический институт (Волжский филиал), ул. Большевистская, 7, 404106 г. Волжский, Российская Федерация, ryabovaev@vgi.volsu.ru, https://orcid.org/0000-0003-4831-0270

Алина Альбертовна Николаева, магистрант, Волгоградский государственный университет (Волжский филиал), ул. 40 лет Победы, 11, 404133 г. Волжский, Российская Федерация, ob.otdel@vgi.volsu.ru, https://orcid.org/0000-0002-7702-6511 